\title{
Agradecimentos de teses e dissertações em Comunicação: as redes da intersubjetividade na produção acadêmica
}

\section{ACKNOWLEDGMENTS OF THESES AND DISSERTATIONS IN COMMUNICATION: THE NETWORKS OF INTERSUBJECTIVITY IN ACADEMIC PRODUCTION}

\section{Luis Mauro Sa Martino ${ }^{1}$}

ORCID: https://orcid.org/0000-0002-5099-1741

(Faculdade Cásper Líbero, Programa de Pós-Graduação em Comunicação. São Paulo, SP, Brasil).

\section{Angela Cristina Salgueiro Marques ${ }^{2}$}

ORCID: https://orcid.org/0000-0002-2253-0374

(Universidade Federal de Minas Gerais, Departamento de Comunicação Social, Programa de PósGraduação em Comunicação. Belo Horizonte, MG, Brasil).

\footnotetext{
${ }^{1}$ Professor do Programa de Pós-Graduação em Comunicação da Faculdade Cásper Líbero e pesquisador da Faculdade Cásper Líbero, SP. Doutor em Ciências Sociais pela PUC-SP. Foi pesquisador-bolsista na Universidade de East Anglia, na Inglaterra e é autor dos livros Métodos de Pesquisa em Comunicação (Vozes, 2018), Teoria da Comunicação (Vozes, 2009), Comunicação e Identidade (Paulus, 2010) e The Mediatization of Religion, publicado pela editora britânica Routledge em 2016, entre outros. E-mail: 1msamartino@ gmail.com

${ }^{2}$ Professora do Programa de Pós-Graduação em Comunicação da UFMG. Doutora em Comunicação Social pela UFMG. É pesquisadora do CNPq e tem pós-doutorado na Universidade Stendhal, Grenoble III, na França. É autora dos livros Apelos solidários (Intermeios, 2017), escrito com Angie Biondi, e Diálogos e Dissidências: M. Foucault e J. Rancière (Appris, 2018), com Marco Aurélio Prado. É organizadora do livro Vulnerabilidades, justiça e resistências nas interações comunicativas (SELO PPGCOM, 2018).

E-mail: angelasalgueiro@gmail.com
} 
Resumo

Este texto delineia aspectos da trama de subjetividades presentes na elaboração de um trabalho acadêmico, tal como representadas nos agradecimentos e dedicatórias de teses e dissertações. Foram examinadas 595 produções defendidas em 2015 e 2016, a partir das quais foi selecionado um corpus de 118 trabalhos para a pesquisa. A análise mostrou três principais eixos de relações: (1) o suporte da a rede familiar e de valores religiosos; (2) vínculos institucionais, dentre os quais se destaca a orientação e as instituições de fomento; (3) o uso do espaço dos agradecimentos para reflexões sobre a jornada de pesquisa. Discute-se, a partir daí, a relação entre práticas epistemológicas e o modo como são tecidas as potências, e enfrentados os limites, do estudo acadêmico.

Palavras-chave: Epistemologia. Afeto. Produção acadêmica. Subjetividade.
Subjective and affective bounds are not usually taken into account in academic research. However, it seems to be an important factor for researcher's development, as epistemological concerns cannot be dissociated from its cognitive and affective environment. This paper examines the acknowledgments and dedications of 118 communication MA and PhD from 2015 and 2016 to outline the main affective bounds and their influence in research. Analysis has suggested three most relevant elements: (1) the friends-and-family supportive web, including religious beliefs; (2) a full range of attitudes towards supervisors, from no reference to emotional gratitude; (3) the institutional and financial support to research. These findings are framed on a background of epistemological research.

Keywords: Epistemology. Affect. Academic Research. Subjectivity.

\section{Introdução}

Dedicatórias e agradecimentos ocupam um espaço incerto - no sentido que Barthes (2000, p.1) utiliza para se referir a um "sujeito incerto" - nos trabalhos acadêmicos. Em teses, dissertações ou outras produções, seu status é ambíguo: estão lá para serem lidos, mas não devem, ou deveriam, ser levados em consideração. Geralmente são uma das partes mais importantes para quem escreve, mas raramente merecem o comentário da banca examinadora. Constam de um trabalho disponível para consulta pública, mas não fazem parte da "contribuição à área". Revelam a trama de circunstâncias e contingências, um entrelaçado de subjetividades e materialidades sem os quais a pesquisa não seria feita - e, no entanto, pouco interessam em termos da pesquisa.

O objetivo deste texto é compreender a trama de subjetividades presentes na elaboração de um trabalho acadêmico representadas nos agradecimentos e dedicatórias. Busca-se olhar para esse "avesso" dos procedimentos epistemológicos objetivados em relações interpessoais de diversos âmbitos, tanto no pessoal e profissional quanto 
acadêmico. Em alguns casos, discutidos no decorrer deste texto, os agradecimentos tomam a forma de longos depoimentos sobre a prática de pesquisa, tecendo reflexões de bastidores sobre os procedimentos adotados. São indicadas as circunstâncias, hesitações, dúvidas e recomeços de toda atividade de pesquisa, revelados os atravessamentos pessoais relacionados responsáveis por isso. É possível ver aí como são tecidas as potências, e enfrentados os limites, do estudo acadêmico e as definições de algumas estratégias de escritura.

$\mathrm{Na}$ origem deste trabalho estão preocupações anteriores, em Martino (2016) e Martino e Marques (2017), relacionadas às questões epistemológicas que se colocam à subjetividade do pesquisador em seu trabalho cotidiano de investigação.

Nas chamadas Humanidades, a atividade de pesquisa se refere diretamente a uma postura ética. Não apenas no sentido de uma "ética na pesquisa" como sinônimo de "boas práticas" ("não plagiar", "citar a fonte", "passar pelo comitê de ética"), mas pelo fato de que estabelecemos relações do "sujeito pesquisador" com outros sujeitos. Isso acarreta sempre o risco de reduzir a alteridade e suas características a um "objeto de pesquisa".

As dificuldades, às vezes próximas da impossibilidade, de relatar o outro enquanto agente e protagonista de suas práticas traz à tona algumas questões sobre o próprio sujeito pesquisador e suas condições de elaboração da prática. Se é possível entender, com Braga (2010), que a elaboração de um projeto de pesquisa é um processo de "tomada de decisões", pode-se supor aí a presença de elementos intersubjetivos.

Tratando-se da pesquisa em Comunicação, optou-se por observar os agradecimentos de teses e dissertações defendidas entre 2015 e 2016 no Banco de Teses e Dissertações da Capes. Foram utilizados como filtros a palavra "mídia" no título e, relacionandose com interações mediadas, indicavam vinculação à Comunicação. A partir dos 595 resultados obtidos, feita uma leitura preliminar, foram selecionados 118 como corpus desta pesquisa. O critério foi a presença de agradecimentos, tamanho, singularidade e a representatividade regional.

A partir de uma leitura analítica foram observados três principais eixos, a partir dos quais este texto também foi estruturado: (1) os vínculos pessoais, sobretudo em relação aos familiares próximos e valores religiosos; (2) os vínculos institucionais, dentre os quais se destaca a orientação; (3) agradecimentos longos, com reflexões sobre a jornada de pesquisa e que se relacionam ao "padecer" das experiências vivenciadas. 
Vale observar que foram suprimidos os nomes próprios e referências diretas aos trabalhos consultados. Mesmo estando públicos em arquivos institucionais, entende-se que o destaque em um contexto acadêmico diferente não é compatível com a proposta ética do trabalho.

\section{Entre o texto e o não-texto: ambiguidades da comunicação do afeto}

Em alguns manuais de formatação, agradecimentos e dedicatórias são chamados de "elementos pré-textuais". Parece existir aí uma indicação de sua ambiguidade: se são elementos "pré-textuais", elas antecedem e, portanto, não são o "texto"; ao mesmo tempo, trata-se de uma escrita, às vezes bastante longa, que denota um "texto".

Essa essa nomenclatura sugere uma dicotomia relativa à validade do que pode ser considerado "texto" na produção acadêmica: dedicatórias e agradecimentos, reservados à subjetividade, são formalmente separados do espaço "objetivo" da pesquisa, da qual as marcas de subjetividade deveriam estar ausentes.

Cynthia Nelson (2005, p. 315) indica como a prática de "escrever abertamente sobre a própria subjetividade" na pesquisa pode aumentar as perspectivas de entendimento e compreensão de uma pesquisa ao indicar as possibilidades e limitações do pesquisador; ao mesmo tempo, assinala que isso pode também ser percebido como "irrelevante, autoindulgente ou insuficientemente crítico". A autora menciona a dificuldade de encontrar o "delicado equilíbrio" entre o desaparecimento e a superexposição da subjetividade do pesquisador.

Daí a situação ambígua das dedicatórias: ocupando um espaço entre o "texto" e o "não-texto", estão ocultas do olhar perquiridor da avaliação acadêmica ao mesmo tempo que revelam suas condições de produção. Um primeiro contraste, por exemplo, é o uso da primeira pessoa do singular, o "eu". Se na escrita acadêmica o uso da primeira pessoa é objeto de extensos debates, ele está "livre" para ser usado nas dedicatórias e agradecimentos; trata-se do espaço autorizado da subjetividade colocado antes do lugar “objetivo", no qual o "eu” tende a ser eliminado ou, pelo menos, questionado.

Sua presença em teses e dissertações é esperada, e a ausência surpreende: não há ninguém a quem se queira expressar seu reconhecimento? Talvez, sintomaticamente, um dos textos a respeito trate o assunto em uma chave de humor crítico: Freitas (2007) ressalta a significativa troca de olhares e comentários entre membros de bancas avaliadoras na ausência de agradecimentos, sobretudo à orientação ou à instituição. 
Ao mesmo tempo, trata-se de um texto inferencial e oblíquo, em contraste com a postura "objetiva" e analítica da academia. Agradecimentos apresentam-se muitas vezes na forma de uma linguagem cifrada, acessível apenas a quem detém os códigos afetivos do autor. Sua leitura é pública, mas sua compreensão, restrita. Mesmo assim é possível inferir, nas pistas oferecidas, presenças e ausências durante a trajetória acadêmica.

Para compreender a trama de relações sociais e afetivas que torna possível o trabalho autoral do pesquisador, esses pequenos textos de agradecimentos e dedicatórias podem ser uma indicação do que Giampapa (2011, p. 138) assinala como hesitações, idas e voltas presentes em processos autonômicos de tomada de decisão (entendendo aqui a autonomia não como processo que isola os sujeitos, mas como processo fundamentalmente relacional e que acentua nossa interdependência).

A dimensão subjetiva do trabalho acadêmico emerge com força redobrada nesses momentos de aparente "liberdade" textual, no qual, geralmente escrevendo depois do trabalho ficar pronto, a pesquisadora ou pesquisador pode, ao nomear aqueles e aquelas à quem são gratos, finalmente abandonar os constrangimentos da escrita acadêmica, a "objetividade" dos resultados e a rigidez das formatações e apresentar-se como sujeito do processo.

Nas escolhas e decisões presentes em um trabalho acadêmico é preciso incluir aí a trama de subjetividades e afetos aí presentes. Vários trabalhos discutem essas questões no âmbito da formação do pesquisador, como Queiroz (1991), Haguette (2002), Tomanik (2004); Becker (2006), Guterres (2006) e Coelho (2013), indicando a necessidade de manter em destaque as negociações implicadas na elaboração de um saber, para compreender as condições concretas de elaboração epistemológica da obra - os procedimentos teóricos, conceituais e metodológicos, têm essa dimensão, como indicam Patterson (2016, p. 202) e Gonzales Rey (2016).

Sabe-se, no folclore das conversas de corredores e cafés nas universidades, a diferença que faz ser orientado por $a$ ou $b$, ou ter aulas com $x$ ou $y$, cursar esta ou aquela disciplina, para o desenvolvimento de uma tese ou dissertação. Ideias, autoras e autores, conteúdos e metodologias resultam do contato com professores, orientadores e colegas. Contato que altera o quadro de vulnerabilidades e constrangimentos que define as experiências e percursos no âmbito da pós-graduação. O bom ou mal desenvolvimento da pesquisa decorrem também dessas relações, que, embora muitas vezes se tornem visíveis no texto, raramente são tornadas objetivas - exceto nos agradecimentos. 
Mais ainda, redes de apoio familiar, profissional e acadêmica são decisivas para a realização de um trabalho. As desigualdades sociais, responsáveis por excluir das práticas acadêmicas todo um grupo de potenciais pesquisadores, parecem se mostrar aí com força redobrada e, em muitos casos, é necessário o auxílio de uma comunidade sensível para que a autora ou autor de uma pesquisa a leve até o final.

Mesmo nesse espaço intermediário, no qual o privado se faz público sem, no entanto, ganhar a condição, o reconhecimento e a validade de "ciência" - status esperado justamente nas páginas após os agradecimentos, nos elementos "textuais" - é possível notar de que maneira se articula, ao redor do trabalho acadêmico, uma gama de relações pessoais, afetos e vínculos dos mais variados matizes.

Argumentamos que os afetos produzem circuitos e fluxos que animam formas de vida delicadamente tecidas em relações, ritmos e tensões que se estabelecem entre a academia e a experiência pessoal. Uma forma de vida, na perspectiva de Ferrarese e Laugier (2018), é fruto de um contínuo trabalho de articulação e sedimentação de práticas, cuidados, afetos e arranjos, uma vez que a vida é uma forma criada enquanto se vive. Nos agradecimentos, os afetos e os cuidados múltiplos expressos através dos gestos de familiares, amigos e conhecidos desenham um circuito de conexões que asseguram as condições de sustenação de corpos, saberes e experiências. Somos convidados a conhecer as redes de cuidado que, de uma maneira que não está formulada a priori em nenhum modelo, tornam possível a textura ética ética e estética da forma de vida que se realiza a partir de algum preço, entre perdas e ganhos.

Mas, nos agradecimentos, uma outra lógica se desenha: nomear e tornar legível (ou mais ou menos inteligível) o circuito de cuidados que garantem uma "vida habitável" durante a produção do trabalho acadêmico permite uma inversão das hierarquias que definem classicamente a forma de vida humana (racionalidade, autonomia, objetividade, etc.), excluindo dessa definição várias experiências afetivas que abrangem tudo o que fazemos para manter a integridade, para preservar e reparar nosso mundo, de modo que possamos nele viver o melhor possível, articulando tudo e todos em um tecido de trama forte e complexa, cuja destinação é manter a vida (Ferrarese e Laugier, 2018).

Assim, consideramos que aquilo que os agradecimentos permitem entrever é justamente um mapa ou uma constelação das ações, escolhas e experiências que permitiram não só o trabalho intelectual realizado durante um período, mas que, a longo prazo, dão sentido à existência e sustentam a confiança necessária no próprio percurso de aprendizagem. 


\section{A rede familiar: presenças e ausências}

A julgar pela incidência desse tipo de agradecimentos, a família é a principal fonte de apoio para mestrandos e doutorandos. Não apenas em termos numéricos, mas sobretudo pelo discurso emocional mobilizado para referências, sobretudo aos pais - à mãe, em boa parte dos casos - e aos cônjuges. Os demais parentes são mencionados de maneira menos frequente.

Esse tipo de procedimento leva a um outro dado relacionado à visibilidade pública e/ou ocultamento das relações pessoais nos agradecimentos. Mães e pais são sempre identificados como tal (“à minha mãe $x$ " ou "aos meus pais, $x$ e $y$ ”), embora, para além desse círculo o agradecimento nem sempre identifica o grau de parentesco ou da relação estabelecida. Em alguns casos, há uma identificação do auxílio prestado ou mesmo à importância em determinado momento:

À minha família que entendeu minha ausência e me apoiou nesse período tão tumultuado, principalmente meus filhos [nome] e [nome], os quais todos os dias perguntavam quantas páginas faltavam. Ao meu companheiro [nome] que assumiu várias de minhas responsabilidades para que eu tivesse tempo de estudar. À minhas irmãs e aos meus pais que cobriram meus filhos de amor enquanto eu estava ausente (Dissertação 09).

Nesses casos, as menções tendem a ser um pouco mais demoradas, explicitando o lugar do pesquisador dentro de uma trajetória coletiva, da família, à qual é creditado o incentivo e a construção de condições - sempre complicadas devido aos fatores históricos de exclusão - para a realização do trabalho.

Ainda nesse aspecto, observa-se a mobilização de redes de afeto familiar para auxiliar os autores - mas sobretudo as autoras - a lidar com as demais atividades, sobretudo quando entra em cena a maternidade. É possível inferir, a partir do agradecimento às mães, irmãs e tias a presença de uma rede de solidariedade nas quais o cuidado com a autora, mas principalmente com filho(s), se mostra decisivo para a realização do trabalho:

Agradeço especialmente às mulheres da minha família que me ajudaram a conciliar os papéis de pesquisadora e mãe: [nome], [nome], [nome] e [nome] (Dissertação 13).

Aos meus filhos, [nome], [nome], [nome] e a neném que está na minha barriga, que me ensinaram que a vida não para por conta de um mestrado. Insistiam em não me deixar 
mergulhada no mestrado o tempo todo, afinal de contas, pra quê isso? Tomar sorvete, andar de bicicleta e ir ao cinema é tão bom quanto estudar. Ao contrário do que muita gente pensa, filhos são o melhor remédio para o stress. Um abraço feliz e espontâneo é simplesmente restaurador, um bilhete dizendo que te ama é encantador e um bolo feito e dedicado a você tem um sabor indescritível (Dissertação 03).

O cenário de reconhecimentos na esfera familiar ganha outros contornos quando o assunto é o relacionamento a dois.

Um ponto inicial é uma mudança do vocabulário: declarações de amor, em suas variadas formas, aparecem relacionadas a nomes e, em alguns casos, ligados a situações reconhecíveis apenas pelos participantes da relação. Raramente a natureza da relação "namoro", "casamento", "companheiro" ou outro tipo - é definida, preferindo, autoras e autores, apenas a menção à pessoa.

Em segundo lugar, ao contrário dos agradecimentos familiares, quase sempre reconhecendo o apoio, as menções românticas comportam outra dimensão - a falta.

Se no que diz respeito a pais e mães a relação é de agregamento e proximidade, no âmbito da relação a dois um dos sentidos construídos pelo texto é a ausência, quando o agradecimento pelo incentivo é acompanhado de desculpas. Em alguns casos, a referência ao parceiro amoroso é pela paciência e compreensão enquanto o autor ou autora atendia às demandas do ambiente acadêmico:

Em segundo lugar, agradeço ao meu companheiro, [nome], pela compreensão e paciência, em momentos de dificuldades e ausência, e ainda por toda a ajuda nesses dois anos de Mestrado (Dissertação 06).

Ao meu esposo [nome], pela compreensão, paciência e incentivo em todo o período do mestrado, nas aulas, no estágio e nos congressos. E também no nosso lar, quando abdiquei da sua companhia para estudar (Dissertação 16).

Agradeço também ao meu esposo [nome], que por muitas vezes foi paciente em meus momentos de ansiedade para concluir os trabalhos e compreendeu os motivos pelos quais precisei ficar ausente para me concentrar nos estudos (Dissertação 01).

A leitura dos textos sugere, aliás, que este é um momento particularmente problemático do trabalho acadêmico, requerendo condições especiais de produção obtidas, muitas vezes, a partir do sacrifício do tempo de convívio familiar. 
É possível observar, nesse ponto, o que poderia ser considerado - com os cuidados necessários a esta observação - um registro de gênero: esse tipo de agradecimento pela paciência durante a ausência parece estar mais presente nas teses e dissertações escritas por mulheres. Há, nesses casos, também pedidos de desculpas e reconhecimento à paciência dos filhos pelo tempo de ausência dedicado ao trabalho acadêmico.

Flávia Biroli (2018) ao falar da divisão sexual do trabalho, comenta que a ênfase na identidade social da mulher como mãe e esposa perpetuaria a divisão tradicional de identidades sociais de gênero, e que dificultaria uma autonomização feminina, por ser a mulher responsabilizada pelos cuidados dos diversos membros da família. Para ela, a presença de um cônjuge é mais determinante para a falta de autonomia da mulher do que a existência de filhos. Assim, o pouco controle da mulher sobre a utilização do tempo de sua vida dificulta seu crescimento e desenvolvimento pessoal, intelectual e profissional.

A crítica feminista se preocupa com o que se passa antes de as preferências serem expressas, ou seja o impacto da opressão e da dominação nas preferências assumidas e escolhas feitas pelas mulheres. Para Biroli, padrões opressivos de socialização alimentariam uma reprodução da moral fundada na obediência. Assim, seria preciso “avançar na compreensão das possibilidades e limites para o exercício da autonomia em contextos nos quais não há coerção, mas constrangimentos sistemáticos, que podem ser sutis, cotidianos e relacionados a estereótipos que são internalizados pelos indivíduos" (2012, p.9).

Um traço cultural relativamente presente, e que pode ser relacionado à esfera privada, são os agradecimentos à Deus. Geralmente colocados em primeiro lugar, indicam a presença de elementos de uma das matrizes religiosas brasileiras. Não há agradecimentos específicos a denominações religiosas, sendo o formato de agradecimento à Deus e à divindades o único traço presente. Neste aspecto, o pluralismo religioso encontra algum espaço:

Agradeço à vida, grande presente de Pachamama, à natureza que partilhamos com todos os seres. Aos anjos da guarda e orixás que me guiam. Ao compartilhar desta caminhada com pessoas e (outros) animais que me ensinaram a ter mais respeito pela terra e pelos filhos dela (Dissertação 14).

A Deus por me proporcionar saúde, sabedoria, paciência e determinação. Esta fé viva que nunca me deixou recuar nem esmorecer, que sempre me encheu de entusiasmo na descoberta de novos conceitos e teorias (Dissertação 16). 
Primeiramente a Deus e a todos os meus guias e protetores espirituais, pela capacidade diária de auxiliarem no aprendizado, pela resiliência e pela paz (Dissertação 05).

Se é possível debater brevemente essa presença, trata-se da irrupção de referenciais do domínio da crença inseridos em um ambiente caracterizado, em sua herança iluminista, por um ceticismo presumido diante de qualquer variedade religiosa. Eliminado do espaço textual da pesquisa, a crença parece retornar no espaço dos agradecimentos como causa primeira das possibilidades do trabalho científico.

\section{As relações de orientação e os vínculos institucionais}

As relações de orientação, no âmbito das vivências acadêmicas, são um objeto crescente de estudos. Trabalhos como os de Schnetzler e Oliveira (2010), Saviani (2012), Wisker (2012) e Martin (2013), destacam a importância dessa relação não apenas para o bom andamento de uma pesquisa específica mas, sobretudo, no desenvolvimento dos pesquisadores e mesmo de sua relação com a academia.

Um primeiro elemento é a ausência, em algumas dissertações e teses, de agradecimentos à orientadora ou orientador. Como destaca Freixo (2001), esse tipo de ausência é particularmente significativa na medida em que a relação de orientação prevê uma convivência mais ou menos contínua por períodos de dois a seis anos. É possível perguntar, prossegue a autora, o que teria acontecido para que essa relação não esteja de modo algum inscrita nas enumerações de gratidão das dissertações e teses. Parece, de qualquer maneira, ser uma ausência bastante significativa.

Em termos intermediários podem ser localizados os agradecimentos que fazem uma referência breve, mas positiva, ao trabalho de orientação. Geralmente compostos de uma ou duas frases, destacam a atuação do orientador nos direcionamentos da pesquisa e no acompanhamento do processo de tomadas de decisão epistemológica durante o trabalho. Em termos numéricos, lembrando que se trata apenas de um indicativo e não de uma pesquisa quantitativa, este tipo de agradecimento é predominante.

No extremo oposto estão expressões mais longas de gratidão ao orientador que, por sua natureza, merecem também um comentário - o exemplo a seguir tipifica o assunto:

Ao meu orientador, Dr. [nome], por ter sido muito mais do que um mentor, mas um pai de alma e amigo. Te admiro e sigo como exemplo. Não encontro palavras para expressar 
minha gratidão, mas posso resumir em um simples "obrigada" tudo que gostaria de lhe dizer. Você trouxe luz para essa pesquisa, todos os dias, nos momentos mais difíceis. Pessoas como você fazem o mundo girar. Obrigada por não desistir de mim, do meu trabalho e mesmo com as dificuldades, por ter me ajudado a crescer e a me encontrar como uma pesquisadora. Ainda pretendo que você sinta orgulho da minha história que, com toda certeza, também é sua! (Dissertação 07)

Em parte das teses e dissertações analisadas, os discursos de gratidão endereçados aos orientadores não destacam apenas o trabalho propriamente dito de "orientar um trabalho acadêmico", naquilo que poderia ser esperado como a indicação de referenciais e direcionamentos em uma perspectiva cognitiva e epistemológica, embora esse tipo de referência também exista:

Ao meu orientador, Dr. [nome], por toda confiança que depositou em mim. Pelo carinho, por cada momento de orientação que na verdade se transformaram em momentos de contemplação, aprendizagem e reflexão. Eu aprendi com meu orientador a olhar o mundo acadêmico de um jeito diferente. Com ele eu compreendi verdadeiramente a contemplar cada leitura, cada capítulo escrito, cada livro lido. Eu fui orientada da forma mais adorável. O professor [nome] é um dos principais responsáveis pelo meu amadurecimento não só dentro da acadêmica, mas amadureci para a vida (Dissertação 15).

Referências de gratidão elogiosa podem ser encontradas, muitas vezes, com referência ao acompanhamento do orientador durante as hesitações e descaminhos da pesquisa, assim como à acolhida e compreensão no sentido de restaurar a autoconfiança do mestrando ou doutorando em situações difíceis. Assim, de maneira talvez um tanto paradoxal, em alguns casos o agradecimento elogioso não parece se ocupar tanto das relações propriamente "pedagógicas" da formação, mas pelo vínculo humano desenvolvido durante a elaboração de uma pesquisa:

A minha Orientadora, [nome], por me ensinar a preencher as páginas em branco de um trabalho. Por vezes fui incentivada a começar pela simples credibilidade e valorização que senti diante de textos pouco lapidados, mas com potencial de se transformar em uma dissertação. Situação esta, que considero muito importante para um aprendiz: sentir-se acreditado. Esse é um grande incentivo. Sem a intenção de me comparar a uma heroína, faço referência a minha orientadora como um mestre, uma mentora nessa jornada que é o mestrado. Por me fazer escrever ou me deixar respirar quando foi preciso, para fazer o 
texto ou o assunto amadurecer e sedimentar em meus pensamentos. A jornada tornou-se mais leve ao lado dela. Sinto gratidão por isso (Dissertação 03).

Ainda em termos institucionais, vale destacar os agradecimentos a outros docentes dos programas de pós-graduação. São destacados, neste caso, outras professoras e professores que contribuíram para a trajetória do aluno. Nas teses e dissertações analisadas esse tipo de agradecimento não costuma ultrapassar uma ou duas linhas.

As universidades e agências de fomento institucional, sobretudo a Capes, são frequentemente creditadas nos agradecimentos. Entidades estaduais, na amostra nãoestatística desta pesquisa, aparecem em menor proporção. Os agradecimentos às instituições se referem sobretudo ao apoio financeiro, muitas vezes indicado como tendo sido decisivo para a pesquisa.

Ainda em termos institucionais, destacam-se agradecimentos ao pessoal técnico e administrativo das universidades, não só às Secretarias e departamentos, mas também, em alguns casos, outros funcionários atuantes no campus:

Aos funcionários da secretaria do PPGCom e às "meninas" (...), [nome ], [nome] e [nome], que deram não apenas o suporte burocrático necessário, mas trataram com delicada atenção minhas demandas em um momento especialmente difícil desta jornada (Tese 01).

Aos amigos da Xerox, [nome] e [nome], por todas as conversas, risadas e lanches (Dissertação 17). [i]

A [nome $]$, [nome ] e [nome], funcionários do PPGCOM, pela solidariedade sem limites (Dissertação 08).

Agradeço também aos funcionários (...),[nome] e [nome], por toda a atenção e prestatividade em todos os momentos em que precisei. Vocês são nota mil! (Dissertação 12).

À Pró-reitoria de Pós-graduação, materializada nas pessoas da então pró-reitora prof. [nome] e a funcionária [nome] pela atenção em assistir socialmente os estudantes estrangeiros (Dissertação 02).

A rede institucional de apoio, embora receba menos linhas nos agradecimentos - e nenhuma menção com teor afetivo-emocional mais destacado - se destaca pela presença 
constante em quase todos as teses e dissertações analisadas, mesmo na ausência de outros endereçamentos:

Aos muitos companheiros de turma PósCom e aos bons amigos que Salvador me deu de presente, obrigado por dividir tantos momentos de alegrias (e desespero coletivo) ao longo destes períodos, sem vocês este tempo não teria sido tão bom (Dissertação 10).

Em um âmbito que transita entre o institucional e o pessoal, as relações com colegas e amigos feitos no curso do Mestrado ou Doutorado ocupam um espaço pequeno, mas geralmente carregado de uma alta afetividade, nos agradecimentos. Em geral, são destacadas algumas pessoas que parecem ter tido uma participação mais próxima, seja colaborando com atividades acadêmicas, seja no apoio pessoal em momentos complicados do trabalho. Existem, mas são raras, menções à "turmas" de colegas, geralmente agrupados em torno de uma disciplina ou semestre letivo.

\section{O agradecimento como relato da jornada}

Em dois dos trabalhos analisados, o espaço dos agradecimentos é utilizado para um relato mais amplo da prática de pesquisa. De todos os tipos e formas de agradecimentos e dedicatórias, esses parecem ser os mais difíceis de categorizar - e, por isso mesmo, talvez os mais representativos do "espaço incerto" dos agradecimentos, em sua dupla dimensão "pública" e "particular". Os caminhos da pesquisa, como destacam Corazza (1996) e Negrão (2014), se interseccionam e cruzam com experiências pessoais e profissionais que dificilmente podem ser separadas, contrastando com a noção de um planejamento rígido das atividades.

Em geral, segundo livros-texto de metodologia, as etapas de realização de uma pesquisa pertencem à "metodologia" ou "procedimentos metodológicos". No entanto, é possível questionar em que medida é possível falar efetivamente de "metodologia", nesse sentido, sem levar em conta todo o contexto que preside essa situação:

Durante essa jornada de pesquisa, eu me senti como um arqueólogo dentro de uma caverna. Eu fiz descobertas incríveis. Compreendi durante esse percurso, que se eu quisesse encontrar a pesquisadora em mim, eu teria que dominar a repulsa das dificuldades que abarca a construção de uma pesquisa acadêmica. Nem sempre o que temos de melhor 
pode ser acessado com facilidade. Nessa caverna em que algumas vezes precisei ficar sozinha, eu garimpei o que há de melhor em mim para realizar o sonho de ser mestre. Um sonho que foi sendo realizado à base de dedicação, esforço e coragem. Fiz tudo da maneira mais bonita, do jeito mais suave e sereno (Dissertação 15).

Ao mesmo tempo, situados nos agradecimentos, portanto antes da pesquisa, esses textos tem um valor diferente em relação ao todo, ainda que revelem situações e procedimentos comuns, dificuldades compartilháveis e, no dizer de Bourdieu (1998), "universalizáveis". No entanto, por sua localização - é possível citar "agradecimentos" de um trabalho científico? - essa troca de experiências não está no âmbito do citável:

Talvez esse seja o momento ou as páginas mais difíceis de escrever. Pensar em tudo o que vivi até aqui, faz-me abrir um sorriso de orelha a orelha e meu coração se enche de gratidão e amor (Dissertação 17).

A opção é apresentar uma espécie de "relatório de campo" da prática de pesquisa, compartilhando as tomadas de decisão, hesitações, avanços e problemas do trabalho ao mesmo tempo em que reconhecem e agradecem as pessoas relevantes em cada um desses momentos. Aproxima-se, nesse ponto, da prática do "diário de pesquisa", conceituado por Borg (2001) ou Barbosa e Hess (2010), como espaço de discussão crítica e autoreflexividade do próprio trabalho:

O mestrado foi um momento muito intenso na minha vida, eu sequer consigo contar as horas que passei no computador, nas estantes da biblioteca, resenhando livros ou escrevendo artigos e capítulos. Agora, relembrando, parece que passou tão rápido, e é só assim que percebo como o tempo voa, escapa pelas nossas mãos e a vida segue seu rumo sem que possamos pará-la. Entretanto, nesse tempo eu aprendi a importância de encerrar os ciclos sem pesar, mas com alegria e coragem. Estes dois anos, foram os mais difíceis e os melhores e a gratidão foi o sentimento que melhor aprendi a cultivar (Dissertação 07).

Dessa maneira, a recuperação das etapas do processo não aparece apenas no tom de síntese ou de agradecimento por algo acabado, mas mostra as incompletudes, os caminhos escolhidos e abandonados, as dificuldades postas pela vida fora da academia - família, trabalho, atividades pessoais, recursos - para a realização de um trabalho acadêmico. E, do mesmo modo, traz para o texto a trama de relações pessoais acionada em cada parte 
desse percurso e que contribuíram, cada uma à sua maneira, para a conclusão - e há, pelo menos em um dos trabalhos, o relato de uma mudança pessoal:

Todo o percurso do mestrado em Comunicação trouxe experiências acadêmicas que ainda não havia vivenciado e que, com certeza, ampliaram minha forma de enxergar a necessidade que sempre senti de cada vez mais buscar o aprendizado e o conhecimento (Dissertação 01).

A escrita dos agradecimentos, neste ponto, se torna ela mesmo problematizada no sentido de escolher não só a quem se vai agradecer, mas também no sentido de enunciar, com os limites de toda e qualquer enunciação, um caminho trilhado de maneira intersubjetiva, na confluência de muitas vozes e práticas. Trata-se não só da narrativa das atividades de pesquisa - que, por si só, já não caracterizaria um percurso metodológico? -, mas também dos modos como a autora se relaciona com os diversos saberes que se entrecruzam no momento de elaborar uma dissertação ou tese.

O mestrado, para mim, foi um dos maiores [desafios] que já ultrapassei. Essas linhas que escrevo nos agradecimentos trazem à minha memória todas as etapas passadas. Mas, em nenhum momento me deparei com um minuto sequer de solidão (Dissertação 04).

Esta dissertação é a parte visível de tudo que foi feito dentro de dois anos de pesquisa, mas ela também é mais do que somente este trabalho (Dissertação 10).

Ampliando a noção de "agradecimento" para um relato detalhado das práticas, são trazidos à tona não apenas as pessoas envolvidas, mas o contexto em que cada uma delas contribuiu com a pesquisadora ou com a pesquisa em si. Devido às suas características particulares no processo de pesquisa, o momento como destacam Hess (2005) e Meira (2016), demanda em particular essa rede de apoio pessoal:

Arrumei meu cantinho debaixo da janela de um quarto no segundo andar da casa das tias, que fica num terreno quase ao lado do sítio dos meus pais. Ali, a labuta da escrita dividia atenção com uma infinidade de cores de pássaros que passavam pela janela à minha frente - e com minhas tias adentrando o quarto de tempos em tempos, trazendo café, água gelada, água de coco e alguma fruta picada pra comer. Ousaria dizer que quase $70 \%$ da tese foi escrita nas quatro semanas em que estive exilada naquele quarto, naquela roça, com aquele amor. Ah! E sem Facebook (Tese 02). 
Forma-se, assim, uma rede de relações nas quais é difícil isolar o momento "subjetivo" do contexto e da trajetória da prática "objetiva" da pesquisa: se existe uma afetividade do conhecimento, os relatos metodológico-contextuais de produção permitem um delineamento, quase uma cartografia, mais ampla.

\section{Considerações finais}

A leitura dos agradecimentos de teses e dissertações em Comunicação nos revelou também alguns traços do processo de construção da autonomia intelectual e afetiva desses pesquisadores e pesquisadoras. A identidade do pesquisador, recorda Heinderyckx (2007, p. 27-29) está em constante mudança, mesmo quando pensada dentro das fronteiras de seu campo de atuação, e recorda a necessidade de levar em consideração esse problema "não apenas em nível individual, mas também coletivo".

Esse percurso não está isento de contradições e vulnerabilidades presentes na esfera subjetiva, sobretudo quando colide com as demandas institucionais de atuação. Rogers (1993, p. 204) indica que a formação do pesquisador está repleta de paradoxos nascidos do contraste entre as condições "objetivas" da pesquisa e as expectativas e desejos que atravessam a subjetividade, bem como o contexto, de pesquisadoras e pesquisadores. Como sintetiza Rosenberg (2017, p. 89), abordando a pesquisa de campo, podemos dizer que esses relatos "revelan la imposibilidad de separar la reflexividad de las estrategias que adoptan y del análisis que realizan sobre las prácticas de los actores".

O modo como são redigidos os agradecimentos nos revela que alcançar a autonomia implica assumir a responsabilidade derivada de nossas conexões, necessidades e vínculos, o que requer olhar com mais vagar e cuidado para as situações, os encontros, os afetos e as práticas de escuta que envolvem o contato e o cuidado com a alteridade.

O cuidado é a manutenção do fio da ordinária, de tudo o que permite à vida de manter sua trama e de encontrar um ritmo viável, sob o preço de mobilizações extraordinárias. Ele é uma sustentação para a vida e para a vulnerabilidade humana, com especial atenção ao que resiste à dor, ao sofrimento e ao desastre, enfrentando as tensões que acompanham o trabalho de manutenção do mundo, e permitindo uma reparação contínua dos espaços em que a vida se esgarça, fratura e ameaça se romper.

De alguma forma, os agradecimentos tendem a buscar uma "humanidade" perdida no desgastante trabalho de pesquisa e escrita: aquele que escreve uma dissertação ou tese também deve ser cuidado e cuidar de outros que o rodeiam, alimentando uma relação 
ética de responsabilidade e atenção contínua que preserva o rosto, a dignidade e a vida. De acordo com Ferrarese e Laugier (2018), o cuidado requer uma sensibilidade aos detalhes que contam nas situações vividas, uma vez que elas não precisam apenas de estudo e teorização, mas também de preservação e de reparação constante de todas as dimensões, elos e articulações que, justamente por não serem negligenciáveis, demandam tanto ou mais que os textos.

Nesse sentido, a concepção de autonomia que nos é apresentada nos agradecimentos não estárelacionada aoindividualismo ouà autossuficiência, características geralmentelidas como intrínsecas a esse conceito. A construção da autonomia intelectual é intersubjetiva, dependente do modo como apreendemos, consideramos e reconhecemos aqueles que, por estarem a nós ligados - pela linguagem ou por outra forma de institucionalidade - nos auxiliam em nossa auto-realização e na realização de nossos projetos de vida, de nossa forma de vida, em uma perspectiva ética, sem desconsiderar as assimetrias, os obstáculos e as vulnerabilidades implicadas no percurso.

Acreditamos que a potência autonômica do percurso formativo da pesquisa acadêmica não se reduz à argumentação, ao "engajamento racional” com os pares ou às habilidades de justificar ou "provar" a eles a validades de algumas hipóteses e métodos, mas abrange também as formas criativas e os "arranjos disposicionais" (para usar o termo de BRAGA, 2018) que elaboram para produzir formas próprias, singulares e autorais de lidar com as dificuldades que se apresentam ao longo da travessia e de suas rotinas.

Por isso, os enunciados que se oferecem a nós nas folhas iniciais dos trabalhos de mestrado e doutorado desvelam alguns dos meandros da fabricação de uma autonomia que se caracteriza como um processo relacional, que evidencia a interdependência dos sujeitos na busca pela auto-realização e realização de projetos pessoais e coletivos. Nesse sentido processual e relacional, a autonomia abrange capacidades decisórias e expressivas ligadas à fabricação de uma linguagem e de códigos próprios (claro, instrumentos sempre polifônicos no diálogo com múltiplos autores e referências) e, ao mesmo tempo, partilhados na construção de bases comuns para a produção de saberes (que aliás não se fazem fora dos vínculos, dos cuidados e das redes materiais e culturais que os tornam possíveis).

Não podemos deixar de salientar que a conquista da autonomia do pesquisador e da pesquisadora depende de componentes sociais e institucionais que, consideradas as assimetrias de poder, configuram lugares de fala nos quais a escuta e a interlocução são permeadas pela "internalização do direito que se tem de falar ou de não falar, da 
desvalorização de certos estilos de discurso e da valorização de outros" (YOUNG, 2001, p. 370).

A tarefa da escrita e as formalidades ligadas à apresentação material de um percurso de pesquisa (que vai muito além dessa representação sígnica ofertada ao escrutínio público) são apontadas como momentos nos quais a mobilização de redes afetivas é crucial para a produção de decisões e escolhas, assim como para a transformação - mas não eliminação) - das vulnerabilidades que informam e dão forma às várias resistências que permeiam a prática da autoria e do protagonismo no trabalho ético e político, individual e coletivo, de criação de saberes.

\section{Referências}

BARBOSA, J. G.; HESS, R. O diário de pesquisa: o estudante universitário e seu processo formativo. Brasília: Liber Livro, 2010.

BARTHES, R. Aula. São Paulo: Cultrix, 1987. ROGERS, Priscilla S. What is a researcher? The Journal of Business Communication, no. 30, Vol. 21993

BECKER, F. D. Reflexões de um quinto de pesquisadora. In: MALDONADO, A. E. et alli. Metodologias de Pesquisa em Comunicação. Porto Alegre: Sulina, 2006.

BORG, S. The research journal: a tool for promoting and understanding researcher development. Language Teaching Research 5,2 (2001); pp. 156-177

BOURDIEU, P. O poder simbólico. Rio de Janeiro: Difel, 1998.

BRAGA, J. L. A prática da pesquisa em comunicação: abordagem metodológica como tomada de decisões. E-Compós. Brasília, v14, n1, jan.-abr. 2010.

COELHO, T. Percursos metodológicos na construção de uma pesquisa sobre as relações comunicativas interculturais na comunidade CS POA. In: BONIN, J. A.; ROSÁRIO, N. M. Processualidades Metodológicas. Florianópolis: Insular, 2013.

CORAZZA, S. M. Labirintos da pesquisa, diante dos ferrolhos. In: COSTA, M. V. Caminhos investigativos. Porto Alegre: Ed. Mediação, 1996. 
EKDALE, B. Negotiating the Researcher: Interstitial, Appropriated, and Digital Identities in Media Production Ethnography. Westminster Papers, Vol. 9, no. 3, Dez. 2013, pp. 7-15.

FERRARESE, E.; LAUGIER, S. Formes de vie. Paris: CNRS Éditions, 2018.

FREITAS, M. E. Viva a tese! Rio de Janeiro: Ed. FGV, 2007.

GIAMPAPA, Frances. The Politics of "Being and Becoming" a Researcher: Identity, Power, and Negotiating the Field Journal of Language, Identity, and Education, 10: 132-144, 2011

GONZALEZ REY, F. Pesquisa Qualitativa e Subjetividade. São Paulo: Cengage, 2016.

GUTERRES, A. Bolsista de iniciação científica: a ponte entre o cidadão e o pesquisador. In: Maldonado, A. E. et alli. Metodologias de Pesquisa em Comunicação. Porto Alegre: Sulina, 2006.

HAGUETTE, T. M. F. Universidade: nos bastidores da produção de conhecimento. In: BIANCHETTI, L.; MACHADO, A. M. N. A bússola do escrever. 3a. Edição. São Paulo: Cortez, 2012 .

HEINDERYCKX, François. The Academic Identity Crisis of the European Communication Researcher. Media technologies and democracy in an enlarged Europe. The intellectual work of the 2007 european media and communication doctoral summer school. The researching and teaching communication series. Tartu University Press, 2007.

HESS, R. Produzir sua obra: o momento da tese. Brasília: Liber Livro, 2005.

HYLAND, K. Disciplinary Identities. Cambridge: CUP, 2012.

MARTIN, M. de S. Que faire des conseils (ou de la absance de conseil) de son directeur de thèse? IN: HUNSMANN, M.; KAPP, S. Devenir chercheur: ecrire une thèse en sciences sociales. Paris: Ed. Ehess, 2013, pp. 63-79.

MARTINO, L. M. S. Da teoria à metodologia: um ensaio sobre a construção de projetos em Comunicação. Revista Comunicação Midiática, Vol. 11, no. 2, Ago-Dez. 2016.

MARTINO, L. M. S.; MARQUES, A. C. S. Afetividade do conhecimento na Epistemologia: a subjetividade das escolhas na pesquisa em Comunicação. Trabalho apresentado no XXVI Encontro Anual da Compós. Faculdade Cásper Líbero, São Paulo, 06 a 09 de junho de 2017. 
MEIRA, A. C. S. A escrita científica no divã. Porto Alegre: Sulina, 2016.

NEGRÃO, S. M. V. A construção da tese: caminhos traçados e sentimentalmente seguidos. In: MACIEL, L. S. M.; VIEIRA, R. A.; SOUZA, F. C. L. (Orgs.) Pesquisa em educação: diferentes abordagens teórico-metodológicas. Maringá: Ed. UEM, 2014.

NELSON, Cynthia D. Crafting researcher subjectivity in ways that enact theory. The Journal of Language, Identity and Education, 4(4), 315-320, 2005.

PATTERSON, Natasha. Emotional scholar-fandoms: negotiating researcher identity in a study with reality show participants. Continuum: Journal of Media \& Cultural Studies, 2016 Vol. 30, No. 2, 195-205

QUEIROZ, M. I. P. Variações sobre a técnica do gravador no registro da informação viva. São Paulo: T.A.Queioz, 1991.

ROSENBERG, Laura. Etnografía del trabajo periodístico. Apuntes sobre la inserción del investigador en la sala de redacción de un diario argentino. Comunicación y Sociedad, Núm. 28, enero-abril, 2017, pp. 87-109.

SAVIANI, D. A pós-graduação em educação no Brasil: pensando o problema da orientação. In: BIANCHETTI, L.; MACHADO, A. M. N. A bússola do escrever. 3a. Edição. São Paulo: Cortez, 2012.

SCHNETZLER, R. P.; OLIVEIRA, C. Orientadores em foco: o processo de orientação de teses e dissertações em educação. Brasília: Liber Livro, 2010.

TOMANIK, E. A. O olhar no espelho: “conversas" sobre a pesquisa em Ciências Sociais. Maringá: Ed. UEM, 2004.

WISKER, G. The good supervisor. Londres: Palgrave, 2012. 